\title{
ARTICULAÇÕES NEOCONSERVADORAS EM TORNO DOS GÊNEROS E DAS SEXUALIDADES NO PLANO MUNICIPAL DE EDUCAÇÃO (PME) DE TEIXEIRA DE FREITAS - BA
}

ARTICULACIONES NEOCONSERVADORAS DE GÉNERO Y SEXUALIDADES EN EL PLAN DE EDUCACIÓN MUNICIPAL (PEM) DE TEIXEIRA DE FREITAS - BA

NEOCONSERVATIVE ARTICULATIONS AROUND GENDERS AND SEXUALITIES IN THE MUNICIPAL EDUCATION PLAN (MEP) OF TEIXEIRA DE FREITAS - BA

DOI: $10.22481 /$ rbba.v1i02.7789

\begin{abstract}
Paulo de Tássio Borges da Silva Universidade Federal do Sul da Bahia- Brasil ORCID: https://orcid.org/0000-0001-7653-1404 Lattes: http://lattes.cnpq.br/7692677995296875 Endereço Eletrônico: paulodetassiosilva@yahoo.com.br

Alessandra Sousa Teixeira Universidade Federal do Sul da Bahia- Brasil Lattes: http://lattes.cnpq.br/1719584808927403 Endereço Eletrônico: alesousat@hotmail.com

João Paulo Lopes dos Santos Universidade do Estado do Rio de Janeiro - Brasil ORCID: https://orcid.org/0000-0002-5582-8097 Lattes: http://lattes.cnpq.br/0102163472677952 Endereço Eletrônico: jpaulouerj@gmail.com
\end{abstract}

ISSN 2316-1205 Vit. da Conquista, Bahia, Brasil / Santa Fe, Santa Fe, Argentina Aprovação: 21/11/2020 \begin{tabular}{ll|l} 
Vol. 09 & Num. 2 & Dez/2020
\end{tabular} p. $102-122$ 
Freitas e Caravelas; e da análise documental com as atas das sessões da Câmara Municipal. A análise indica articulações neoconservadoras entre membros do legislativo, representantes religiosos da igreja católica e igrejas evangélicas, bem como utilização de discursos psicológicos como "validação científica" na tentativa de silenciar as questões de Gêneros e Sexualidades no PME do município.

Palavras-chave: Gêneros; Neoconservadorismo; Sexualidades.

\title{
RESUMEN
}

Este artículo tiene como objetivo analizar las articulaciones neoconservadoras en torno a Géneros y Sexualidades en la construcción del Plan de Educación Municipal Teixeira de Freitas (PME), ubicado en el extremo sur de Bahía. Para ello utilizamos la etnoprintgrafia (BORGES, 2019) de periódicos virtuales, páginas de internet, como la de la diócesis de Teixeira de Freitas y Caravelas; y el análisis documental con el acta de las sesiones del Ayuntamiento. El análisis señala articulaciones neoconservadoras entre diputados, representantes religiosos de la Iglesia católica e iglesias evangélicas, así como el uso de discursos psicológicos como "validación científica" en un intento de silenciar los temas de Género y Sexualidad en lo PME del municipio.

PALABRAS CLAVE: Géneros; Neoconservadurismo; Sexualidades; Teixeira de Freitas.

\begin{abstract}
This article aims to analyze the neoconservative articulations around Genders and Sexualities in the construction of Teixeira de Freitas Municipal Education Plan (MEP), located in the extreme south of Bahia. For this, we use ethno-printing (BORGES, 2019) of virtual newspapers, internet pages, like Teixeira de Freitas and Caravelas diocese's page; and the documentary analysis with the minutes of the sessions of the City Council. The analysis indicates neoconservative articulations between members of the legislature, religious representatives of the Catholic church and evangelical churches, as well as the use of psychological discourses as "scientific validation" in an attempt to silence the issues of Gender and Sexuality in the municipality's MEP.
\end{abstract}

Keywords: Genres; Neoconservatism; Sexualities; Teixeira de Freitas. 
ARTICULAÇÕES NEOCONSERVADORAS EM TORNO DOS GÊNEROS E

DAS SEXUALIDADES NO PLANO MUNICIPAL DE EDUCAÇÃO (PME) DE

TEIXEIRA DE FREITAS - BA

\section{CONSIDERAÇÕES INICIAIS}

$\mathrm{Na}$ última década a interpelação e articulação de grupos religiosos na educação se intensificaram, passando a surgir grupos como o Escola Sem Partido (ESP) e grupos vinculados às igrejas cristãs (Católica e Evangélicas), que passaram a pressionar representantes do executivo e legislativo no que classificam como defesa dos valores das tradições familiares cristãs. Nessa cruzada na defesa de tais valores, os debates e as pautas identitárias de gêneros e sexualidades na educação passaram a ser o alvo, caracterizando o que estamos entendendo como articulações neoconservadoras.

Apple (2000) vem refletindo as articulações neoconservadores nos Estados Unidos, tentando estabelecer seu surgimento a partir das décadas de 1960 e 1970, sendo os neoconservadores entendidos como um dos grupos da chamada "Nova Direita" (LIMA; HYPÓLITO, 2019). Para Lima e Hypólito (2019), “a Nova Direita constitui uma aliança, principalmente, entre neoconservadores e neoliberais, central para o desmantelamento do Estado de Bem-Estar e para a criação de uma nova forma de administrar o Estado quando da crise de 1970 nos países centrais ao capitalismo" (LIMA; HYPÓLITO, 2019, p. 3). Para Apple (2000, 2001, 2013) a Nova Direita nos EUA é constituída pela liderança dos neoliberais com os interesses direcionados à economia, enxergando a escola como um mercado competitivo; os neoconservadores saudosistas dos valores de uma certa tradição cultural, que nesse caso é a ocidental, postulando que a "escolarização deve ser mais competitiva com os estudantes a serem re-estratificados através daquilo que é visto como conhecimento e testes de desempenho 'neutros"” (APPLE, 2001, p. 7); os populistas autoritários formados por grupos evangélicos defensores da família, "que pretendem o regresso àquilo que acreditam ser "a" tradição Bíblica como base do conhecimento, textos sagrados e autoridade sagrada. Habitualmente, esta facção da aliança desconfia muito das questões multiculturais no currículo" (APPLE, 2001, p. 7); e a nova classe média profissional e administrativa, composta por trabalhadores de distintas matizes étnicas, raciais, de gênero e orientação sexual, preocupadas com a ascensão social, e que não concordam com todas as pautas dos grupos anteriores, alegando não possuírem uma agenda ideológica.

Como abordamos no início desse texto, no Brasil as articulações desses grupos abordados por Apple $(2000,2001,2013)$ também se fazem presentes, compondo alianças e plataformas políticas nos níveis federal, estadual e municipal, onde a retórica passa a ser o ataque aos parcos direitos conquistados pelos movimentos sociais identitários, culminando na Revista RBBA Revista Binacional Brasil Argentina 
DAS SEXUALIDADES NO PLANO MUNICIPAL DE EDUCAÇÃO (PME) DE

TEIXEIRA DE FREITAS - BA

tentativa de silenciamento das questões de raça, etnia, gêneros e sexualidades na educação, como a extinção da Secretaria de Educação Continuada, Alfabetização, Diversidade e Inclusão (SECADI) no governo de Jair Bolsonaro, que operava na construção de políticas de formação continuada, construção de diretrizes e materiais didáticos nos contornos da diferença. Para Lima e Hypólito (2019) "houve um entendimento, por parte de grupos conservadores, de que os movimentos pelos direitos civis e sociais - marcantes nos anos de 1960 - haviam provocado uma degeneração social e era preciso retomar valores que tinham como base, centralmente, a família, a moral e o indivíduo “(LIMA; HYPÓLITO, 2019, p. 4).

Neste sentido, perseguindo essas articulações neoconservadoras no campo educacional, esse texto pretende analisar as articulações neoconservadoras em torno dos gêneros e das sexualidades no Plano Municipal de Educação de Teixeira de Freitas - Bahia. Para tanto, utilizamos da etnoprintgrafia (BORGES, 2019) de jornais virtuais, páginas de internet, como a da diocese de Teixeira de Freitas; e da análise documental de atas das sessões da Câmara Municipal. A etnoprintgrafia está localizada na netnografia ou etnografia virtual, e consiste numa metodologia de registro dos processos ciberculturais, atuando na composição de paisagens híbridas ciberculturais em diferentes ciberespaços. A etnoprintgrafia pode ser útil no registro de textos virtuais (escritos e imagéticos) até vídeos com performances, challenges, GIFs, entre outros.

Assim, na primeira parte desse artigo traremos as articulações em torno da "ideologia de gênero" e Escola Sem Partido, e como essas se resvalaram na exclusão da educação em gêneros e sexualidades do Plano Municipal de Educação (PME). Na segunda parte, buscaremos construir a rede de articulação neoconservadora no município de Teixeira de Freitas.

\section{Articulações em torno da "Ideologia de Gênero" e Escola sem Partido}

A participação de grupos do movimento LGBTQIA+ na política brasileira ganhou uma maior visibilidade a partir da década de 1990 com a política antiaids, tendo uma maior notoriedade a partir dos anos 2000 com políticas sociais como o Programa Brasil sem Homofobia e a construção e participação em conferências municipais, territoriais e nacionais, bem como conselhos LGBTQIA+, aprovação do casamento civil igualitário, legislação específica para adoção de crianças por casais homoafetivos, criminalização da homofobia, entre outras legislações conquistadas pelo movimento. Todavia, se por um lado o movimento LGBTQIA+ tinha alguns dos seus direitos conquistados, a "organização conservadora se 
DAS SEXUALIDADES NO PLANO MUNICIPAL DE EDUCAÇÃO (PME) DE

TEIXEIRA DE FREITAS - BA

revigorou, expressando-se com mais força no Congresso Nacional. Aqui, se tornou central a atuação da 'bancada evangélica', a forma de articulação mais importante entre parlamentares, partidos e igrejas conservadores" (TOITIO, 2017, p. 2).

No que concerne às políticas públicas de educação no Brasil, sobretudo em anos mais recentes, estas têm sido influenciadas por articulações políticas construídas em torno do discurso de uma educação fracassada, permeada por doutrinação política e ideológica. Esse é o fundamento de uma nova ordem que reivindica a liberdade, a justiça, um modo de vida livre e de uma sociedade conectada à tradição. Nesse cenário, um dos movimentos mais significativos é aquele embalado pelo avanço de vozes assumidamente conservadoras.

O recrudescimento de reivindicações conservadoras, instigadas por parlamentares e reacionários religiosos que defendem a bandeira da "família tradicional, da moral e dos bons costumes" em contraposição às questões de gênero e sexualidade, tem impactado as elaborações de políticas educacionais hodiernas, culminando na tentativa do apagamento e esterilização das diferenças nos currículos. À guisa de exemplo, é pertinente localizar duas políticas centrais: o Plano Nacional de Educação - PNE (2014-2024) e a Base Nacional Comum Curricular - BNCC aprovada em 2017. Ambos são documentos normativos cuja intenção é orientar a organização dos currículos na esfera estadual e municipal. Tais documentos são produtos de disputas por significação no currículo e foram calculados a partir de princípios das racionalidades neoliberais e conservadoras.

Nessa esteira, de acordo com Rodrigues e Facchini (2018), a partir de 2013 iniciam-se movimentações mais sólidas no intuito de influenciar os textos legais das políticas educacionais brasileiras, notadamente no que se relaciona à inclusão de gênero e diversidade sexual no texto do Plano Nacional de Educação - PNE (2014-2024). Tais movimentações se localizavam na plataforma de reivindicações dos movimentos feministas e LGBT. Reivindicações estas que se centravam na diretriz da promoção da igualdade e da afirmação da diversidade. Entretanto, essas propostas, no percurso de construção do PNE, foram transformadas, por grupos religiosos e conservadores, numa categoria nociva nomeada "ideologia de gênero", que "seria uma verdadeira ameaça à família tradicional, heterossexual, natural” (RODRIGUES, FACCHINI, 2018, p. 99).

É importante ressaltar que a defesa dessa agenda por grupos religiosos brasileiros tomou fôlego na década de 1990, sobretudo a partir da mobilização das igrejas neopentecostais no empreendimento de eleger seus pastores a cargos políticos. Contudo, Miguel (2016) sinaliza 
DAS SEXUALIDADES NO PLANO MUNICIPAL DE EDUCAÇÃO (PME) DE

TEIXEIRA DE FREITAS - BA

para o fato de que, ainda que se faça referência a esses grupos como "bancada evangélica", é preciso registrar que esse conjunto, além de conformar denominações protestantes diversas, exclui a presença do segmento mais conservador da Igreja Católica.

O fundamentalismo católico, através de seus ataques às questões de gêneros e sexualidades, inaugurou a terminologia "ideologia de gênero" como estratégia conservadora para tratar das problematizações das relações de gênero. É importante evidenciar que gênero surgiu no ambiente acadêmico estadunidense nos anos de 1970 como forma de indicar a diferença entre os papéis sociais atribuídos a homens e mulheres. Logo, gênero passou a ser denunciado, no ambiente católico conservador americano, como uma ameaça e subversão dos arranjos familiares convencionais.

A percepção dessa suposta ameaça se potencializou e chamou a atenção da Santa Sé, sobretudo a partir das conferências internacionais sobre população e desenvolvimento no Cairo em 1994, e sobre as mulheres, em Pequim, no ano de 1995. Ambas as conferências apresentaram a igualdade de gênero como questão preponderante a ser considerada (MIGUEL, 2016). Nessa esteira, a Igreja Católica formalizou, explicitamente, o inimigo a ser combatido, o qual, no Brasil, recebeu o nome de "ideologia de gênero". Uma invenção que busca polemicamente deslegitimar um campo de estudos, e que obteve apoio de segmentos neopentecostais.

O debate em torno de gênero e sexualidade se intensificou nos últimos tempos e ganhou foco em 2014, quando tramitava no Congresso Nacional a proposta do novo PNE. Após deliberações nas Conferências Nacionais de Educação sobre equidade de gênero e o respeito à diversidade sexual (realizadas em momentos anteriores ao referido Plano), o Projeto de Lei $\mathrm{n}^{\circ}$ 8.035/2010 em seu Art. $2^{\circ}$ estabelecia, dentre outras, a diretriz III que tratava da superação das desigualdades educacionais, atentando para a promoção da igualdade racial, regional, de gênero e de orientação sexual, bem como a erradicação de todas as formas de discriminação.

O teor dessa diretriz suscitou, assim, a acentuação de polêmicas que a afetaram (AMARO, 2017). Segundo o autor, "essa foi a oportunidade para que setores religiosos fundamentalistas, católicos e conservadores orquestrassem verdadeira 'sinfonia de improbidades"” (AMARO, 2017, p. 141). As bancadas formadas por políticos religiosos contestavam que, ao permitir a "ideologia de gênero"i nas escolas, a definição de homem, mulher e de família seria maculada e os valores morais deturpados. 

DAS SEXUALIDADES NO PLANO MUNICIPAL DE EDUCAÇÃO (PME) DE TEIXEIRA DE FREITAS - BA

A terminologia "ideologia de gênero" ganhou capilaridade por parte da Igreja Católica, sendo reiterada pelas dioceses e chegando aos interiores, como a cidade de Teixeira de FreitasBA, onde seu combate no PME foi utilizado como bandeira de fé. A imagem abaixo printgrafada no site da Diocese de Teixeira de Freitas - Caravelas ilustra uma cruzada às questões de gêneros e sexualidades pela instituição. Vejamos:

Imagem 01 - Etnoprintgrafia - Campanha Antigênero da Diocese

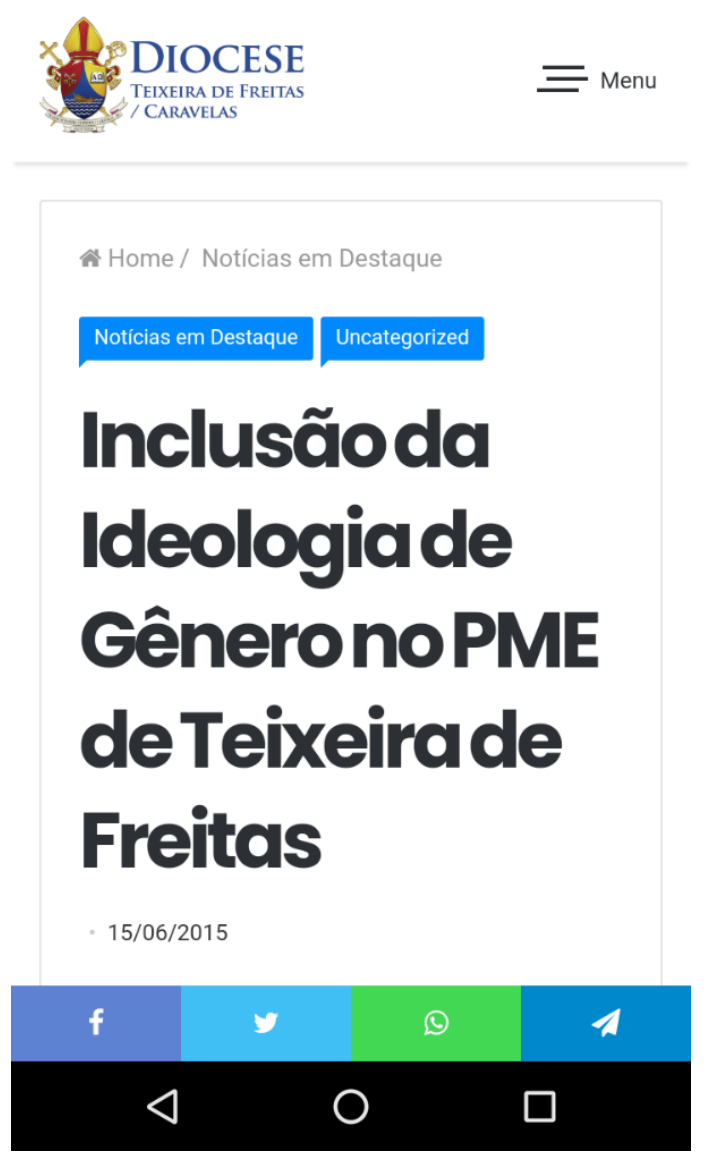

Vejamos alguns trechos trazidos na matéria:

No dia 12 de junho ocorreu na Câmara Municipal de Teixeira de Freitas uma reunião com líderes religiosos e da sociedade civil, dentre eles o Bispo Diocesano Dom Carlos Alberto, para discutir o Plano Municipal de Educação (PME).

Fizemos contato no dia 14 de junho com o Vereador Edinaldo Rezende (PT), presidente da Comissão dos Direitos Humanos, e participante da comissão de construção do Plano Municipal de Educação, e este afirmou à nossa redação que os parágrafos que incluíam a ideologia de gênero foram totalmente retirados do texto. Segundo o vereador, o texto reformulado, que não inclui a ideologia de gênero, será votado no dia 16, terça-feira, na câmara municipal de Teixeira de Freitas. 
Mesmo assim, a Igreja recomenda que todos os católicos pressionem seus representantes políticos para que entendam que este tipo de proposta não é de interesse da maioria da população. O Brasil ainda é um país predominantemente Cristão, porém vemos cada vez mais políticas que vão contra nossas tradições e valores. Portanto, os políticos eleitos pelos católicos precisam atuar no cumprimento da vontade dos seus eleitores (DIOCESE DE TEIXEIRA DE FREITAS/CARAVELAS, 2015). ${ }^{\text {ii }}$

A intenção de trazermos esta etnoprintgrafia e descrição da matéria veiculada no site da diocese se configura como uma maneira de mostrar a influência de setores conservadores da Igreja Católica em Teixeira de Freitas - BA nas discussões sobre a inclusão das questões de gêneros e sexualidades no currículo escolar. Segundo os representantes da igreja e do poder legislativo municipal, a inserção das questões de gêneros e sexualidades no PME colocaria em perigo os valores cristãos. Contudo, é necessário trazer para a discussão, com base nos dispositivos legais, que os textos finais da Conferência Nacional de Educação Básica (CONEB) de 2008 e das Conferências Nacionais de Educação (CONAE) de 2010 e 2014 não referenciam a utilização do termo "ideologia de gênero" nos planos estaduais e municipais de educação, tratando como equidade entre os gêneros e o respeito à diversidade sexual.

A tonificação do discurso da "ideologia de gênero", notadamente na fração conservadora da sociedade brasileira, possibilitou a visibilização e expressão parlamentar do movimento autointitulado Escola sem Partido (ESP). Conforme exposto na página eletrônica do ESP ${ }^{\mathrm{iii}}$, tal movimento se compreende como uma iniciativa compartilhada entre estudantes e pais inquietos com o nível de propagação político-ideológica das instituições educacionais do Brasil, do ensino básico ao superior. Dessa forma, como afirma o próprio movimento, este foi instituído para expor o suposto e grave problema da instrumentalização do ensino para fins políticos, ideológicos e partidários.

Segundo Macedo (2017, p. 509), este é um movimento que chama a atenção para os "princípios religiosos, a defesa da família em moldes tradicionais e a oposição a partidos políticos de esquerda e de origem popular". No entanto, é necessário destacar que, a princípio, a objeção conservadora religiosa às questões de gênero era independente do movimento ESP, e surgiu com o registro de combater a "doutrinação marxista" nas escolas. A confluência da denúncia da "doutrinação marxista" com a refutação da suposta "ideologia de gênero" seguiu, desse modo ao senso da conjuntura do ESP. Assim, a fusão ocorreu mobilizada por reacionários de extrema-direita, para quem a ruptura da moral sexual padronizada é uma estratégia comunista (MIGUEL, 2016).

Revista RBBA $\mid$ Revista Binacional Brasil Argentina 
DAS SEXUALIDADES NO PLANO MUNICIPAL DE EDUCAÇÃO (PME) DE

TEIXEIRA DE FREITAS - BA

Ao passo que a "ideologia de gênero" se justapõe à "doutrinação marxista", o discurso do ESP toma outros rumos. "A defesa de uma educação 'neutra', que era predominante até então, cede espaço à noção da primazia da família sobre a escola” (MIGUEL, 2016, p. 601) e o foco principal passa a ser a "ideologia de gênero", vocábulo reduzido a slogan e "defendido por vários grupos reacionários e transformado em vários projetos de lei” (PARAÍSO, 2018, p. 220), com intenções óbvias de controlar o currículo, amordaçar professores/as e dificultar a enunciação da diferença.

As tensões presentes quando do processo de discussão da proposta do PNE influenciaram a sua versão final, havendo por isso reformulações em sua redação, e por consequência a retirada da menção à igualdade racial, regional, de gênero e orientação sexual do texto oficial. As controvérsias estabelecidas a partir das discussões que circundaram a aprovação do PNE - mediante instituição da Lei $n^{\circ}$ 13.005/2014, sancionada pela então presidenta Dilma Rousseff - se deslocaram para as esferas estaduais e municipais, suscitando em alguns estados e municípios disputas e debates análogos ao que foi presenciado a nível nacional.

Para tanto, o novo PNE é parâmetro para a elaboração de outras políticas de educação, a exemplo da BNCC. O processo de construção da Base foi permeado por embates e ações mais consequentes, mediante incursões do movimento ESP e outros agentes políticos, os quais se esforçaram por interferir nas políticas públicas de educação com o objetivo de regular os currículos (MACEDO, 2014). Nesse sentido, as pressões provocaram a exclusão, no texto promulgado pelo Conselho Nacional de Educação $(\mathrm{CNE})$, de temas referentes à diversidade $\mathrm{e}$ à pluralidade cultural (MACEDO, 2018). Os vetos basearam-se nas supostas "posições políticas entendidas por movimentos como o de esquerda, questões de gênero e sexualidade, cultura negra (referida como religião), entre outras" (MACEDO, 2018, p. 2).

É notório que as contestações neoconservadoras, reacionárias e religiosas objetivaram ao enfrentamento das demandas de movimentos sociais diversos, principalmente de pautas reivindicadas pelo movimento LGBT, as quais incluíam "o combate à violência, ao preconceito e à discriminação, o respeito à diversidade sexual, a criminalização da homofobia e a despatologização do segmento transexual" (AMARO, 2017, p. 141), como também do posicionamento referente aos enfrentamentos das mulheres contra o machismo, o sexismo, a violência e o feminicídio (AMARO, 2017). 
DAS SEXUALIDADES NO PLANO MUNICIPAL DE EDUCAÇÃO (PME) DE

TEIXEIRA DE FREITAS - BA

O fundamentalismo que sustenta tais contestações se justifica mediante compreensão de que existe uma verdade, uma verdade sacralizada revelada, e que cessa qualquer chance de debate. Isso aponta para o modo como os neoconservadores religiosos se veem como aqueles que podem dizer a verdade, portadores de uma epistemologia santificada e verdadeira que os autoriza a decidir sobre o que é benéfico para a sociedade. Assim fazem uso do poder político para coagir e constranger. Esse conservadorismo ameaçador, ostentado, sobretudo, pela extrema direita cristã, não organiza apenas a autoridade do Estado afiançado pelo neoliberalismo, mas, como afirma Brown (2019), estrutura seu alargamento e alcance estendido.

Este quadro mostra a justaposição da moralidade às forças reacionárias que se constituíram a partir das mágoas suscitadas pelos deslocamentos da família "tradicional”, da masculinidade branca heteronormativa e da autenticidade étnico-racial considerada intocável. À medida que determinados agentes, movimentos e organizações sociais demandam por questões de sexualidades não normativas, gênero, raça, feminismo, outras versões de família, artes, educação, etc., as forças conservadoras e religiosas se deparam com o niilismo e o ressentimento, e isso produz o ódio de um mundo visto como aquele que deseja destruí-las. Trata-se de ressentimentos, feridas não estancadas que vão subsidiar uma política perene de vingança. Uma política de enfrentamento para aqueles tidos como responsáveis por zombar e deslocar os valores tradicionais e a imagem ilibada da masculinidade branca - movimentos LGBTQIA+, feministas, multiculturalistas, etc.

Quando o ressentimento emerge, o que possivelmente acontece é a motivação à vingança. Isso significa dizer que os que se sentem destronados se mobilizam. Eles "só têm vingança, sem saída, sem futuridade" (BROWN, 2019, p. 217). O que implica naquilo que podemos presenciar, a título de exemplo, no Brasil de hoje, em que a religião cristã é tratada como mercadoria e se serve de arma de fogo. A retórica do patriotismo limita-se ao combate à diferença e ao apoio para aquele que representa a vingança, o qual corporifica a dor dos destronados e os representa. Não importa que política ele siga, o que ele seja ou pratica, desde que faça acontecer o banimento daquilo que seus apoiadores julgam ser o culpado por suas dores, e promova ideias e valores nacionalistas cristãos (BROWN, 2019).

Nesse processo, os fundamentalistas com suas proposições, como as advogadas pelo movimento ESP, por exemplo, seguem gritando contra direitos e políticas consideradas, por eles, como corroedores da moral, dos valores cristãos e da família tradicional. Desse modo se 
DAS SEXUALIDADES NO PLANO MUNICIPAL DE EDUCAÇÃO (PME) DE

TEIXEIRA DE FREITAS - BA

opõem ao direito ao aborto, às políticas de enfrentamento e combate à homofobia, racismo, etc.

Se mobilizam, alinhando suas demandas às diversas contestações conservadoras nas casas legislativas, como as defendidas pelos agropecuários e aqueles que reivindicam o armamento, unindo forças para o fortalecimento de todos. Esse movimento conta ainda com a significativa atuação política de pastores na potencialização dessas demandas, tanto no Congresso quanto na mídia.

No próximo tópico, apresentaremos as articulações neoconservadoras no município de Teixeira de Freitas- BA, numa tentativa de mostrar como essas articulações se espraiaram para os municípios dos interiores brasileiros, construindo políticas antigêneros e sexualidades nos Planos Municipais de Educação (PME’s).

\section{Articulações Neoconservadoras no Município de Teixeira de Freitas - BA: entre o Bispo, o Psicólogo, os Pastores e os Vereadores}

Durante o mês de junho do ano de 2015, o município de Teixeira de Freitas teve suas ruas, igrejas, feiras, praças, escolas e a Câmara Municipal perpassadas pela discussão em torno das questões de gêneros e sexualidades. No entanto, cabe pontuarmos que as articulações neoconservadoras já vinham sendo tecidas no município, como podemos observar na printgrafia e no trecho da matéria jornalística de julho de 2010:

Imagem 02: Etnoprintgrafia - Repúdio ao Grupo Gay da Bahia.

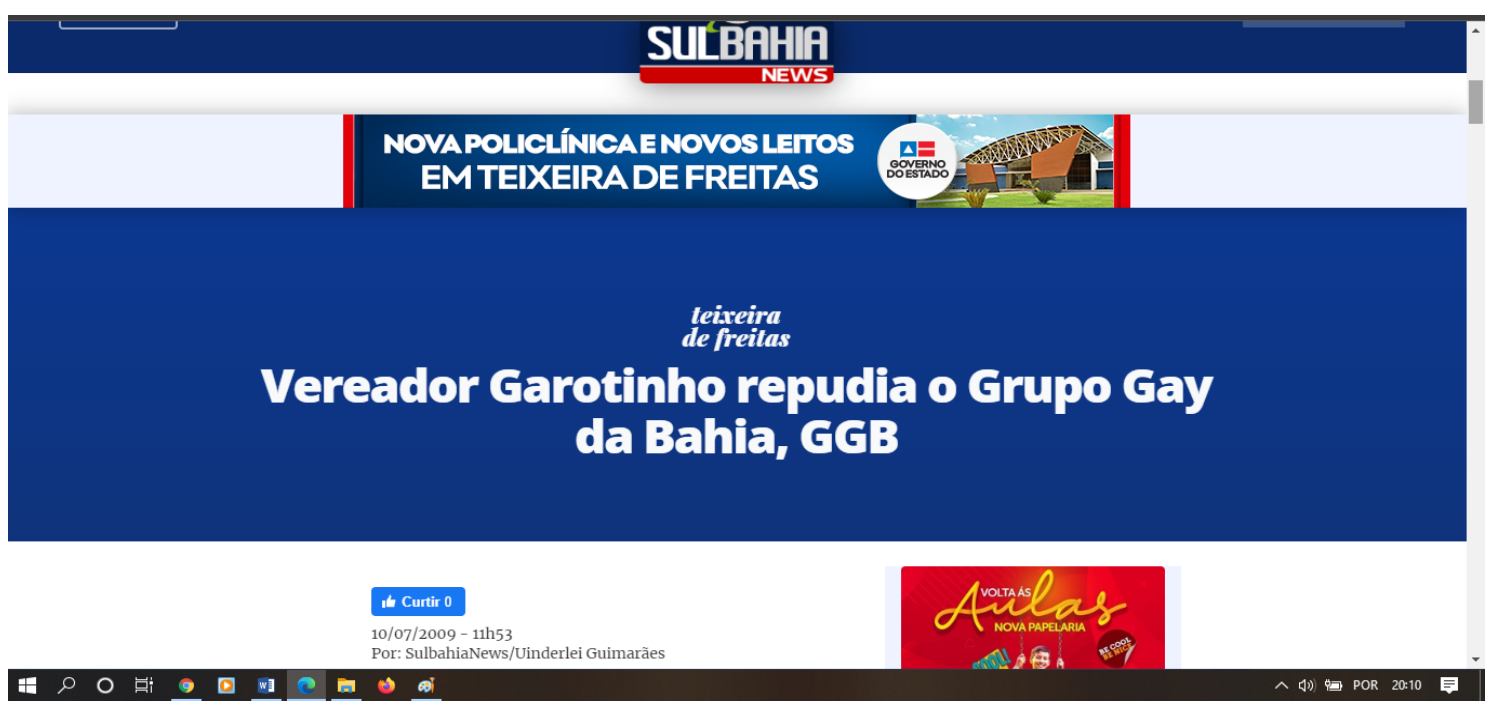

Fonte: Jornal SulBahia News

\begin{tabular}{l|l} 
Revista RBBA & Revista Binacional Brasil Argentina
\end{tabular} 
Vejamos os trechos da matéria:

Dentre os projetos de lei, pedidos de providências e indicações, o que mais se discutiu na sessão dessa terça, 27 de julho, foi a moção de repúdio ao Grupo Gay da Bahia, (GGB) enviada a Câmera pelo vereador e candidato a deputado estadual, Júlio César de Oliveira Cavalcante, Garotinho (PSC).

A Moção no 61/2010 que repudia o Grupo Gay da Bahia pela frase "A Bahia é GAY", veiculada no site www.ggb.org.br, teve aprovação quase unânime, (6 votos), se não fosse o vereador José Henrique Gonsalves da Cruz (PT). Em viagem, os vereadores Lula, Gilberto, Genivaldo e Ednaldo, não compareceram à reunião do legislativo municipal.

Durante a palavra franqueada, o vereador Henrique, rebateu, e disse que a moção constitui discriminação, ferindo o artigo $3^{\circ}$, inciso $4^{\circ}$ da Constituição da República Federativa do Brasil, (promover o bem de todos, sem preconceitos de origem, raça, sexo, cor, idade e quaisquer outras formas de discriminação). "Nós, enquanto poder, não podemos aprovar algo que fere a constituição", comentou o vereador.

$\mathrm{O}$ vereador Garotinho argumentou, e disse que a frase é um desrespeito às famílias baianas, "eles podem ser gays, mas não podem generalizar. A liberdade de expressão não tem o direito de optar pela opção sexual de toda a Bahia", disse.

Usando a "parte", o vereador Henrique, disse que ao ler a frase interpretou de forma diferente e não como generalização. "A meu ver, não foi uma generalização, a interpretação que tive é que a frase quer dizer que na Bahia também existem gays", disse.

Em um tom irônico, o vereador Garotinho disse que entende o ponto de vista favorável do vereador Henrique, quanto às ações do GGB, e repudiou também, as paradas gays, chamadas por ele de "orgias ao ar livre".

$\mathrm{O}$ vereador Henrique voltou a falar e contestou a questão de ordem à presidente da Câmara Marta Helena, apontando que o vereador Garotinho, além de tratar a discussão de forma irônica, ainda teria distorcido sua fala. Henrique explicou que sua fala constituiu em uma explanação referente aos princípios da constituição e que em momento algum deixou transparecer favorecimento ou opinião diferente às ações do GGB (SULBAHIA NEWS, 2010). ${ }^{\text {iv }}$

Poderíamos começar perguntando: o que mobiliza um vereador que tem como função autorizar despesas do executivo, fiscalizar a execução dessas despesas e legislar em prol do bem comum social, a apresentar como projeto de lei uma Moção de repúdio a um grupo que é uma das referências na defesa dos direitos humanos da população LGBTQIA+ no Brasil? O Grupo Gay da Bahia foi fundado em 1980, é o primeiro grupo em defesa da população LGBTQIA+ na Bahia e um dos mais antigos do Brasil, registrado como sociedade civil sem fins lucrativos e de utilidade pública, que durante décadas tem realizado atividades, oferecendo cursos profissionalizantes e construindo pesquisas, sendo a instituição responsável pelo 
DAS SEXUALIDADES NO PLANO MUNICIPAL DE EDUCAÇÃO (PME) DE

TEIXEIRA DE FREITAS - BA

levantamento dos índices de violência, produzindo anualmente relatórios sobre pessoas LGBTQIA+ mortas no Brasil.

A matéria traz a representação das reivindicações baseadas num neoconservadorismo que já se instalava no legislativo municipal. Após a sessão da câmara municipal do dia 27 de julho de 2010, ativistas LGBTQIA+ do município foram até câmara municipal para protestarem contra a nota do vereador. Sendo o ato registrado no fragmento abaixo do jornal:

Também conversando com Garotinho, ele nos garantiu que não quis manifestar qualquer homofobia ou preconceito contra os gays. $\mathrm{O}$ vereador explica que simplesmente acha que a Bahia não é gay e que manifestou uma posição contrária a essa interpretação, (feita pela turma do arco íris). $\mathrm{O}$ vereador disse que se manifestou contrário a isso, além de por convicção pessoal, por cobrança de eleitores seus, mas sem homofobia e sem ofensas. E explica: "intolerantes são eles, que usaram um cadeirante para ir à Câmara e jogar purpurina em mim. Não reagi em respeito ao meu mandato e em respeito aos presentes à sessão (JORNAL O SOLLO, 2010). ${ }^{v}$

O cadeirante que o vereador se refere é o ativista Hermington Maurício de Andrade, que na época era membro do Corphus, Coletivo Popular Universitário de Discussão de Gêneros e Sexualidades, fundando por estudantes da Universidade do Estado da Bahia - UNEB, Campus de Teixeira de Freitas. Hermington carregava durante a sessão da câmara o cartaz com os dizeres: "O que mata é sua homofobia", e proferia a frase diante dos presentes: "Essa casa está da sua soleira até o teto manchada com o sangue de LGBT's". E durante a fala do vereador Garotinho, dirigiu-se à sua presença, atirando purpurina no mesmo.

No ano de 2011, novamente o vereador Garotinho utilizou o seu mandato para atacar as demandas e as políticas identitárias no tocante às questões de gêneros e sexualidades. Vejamos a etnoprintgrafia abaixo: 


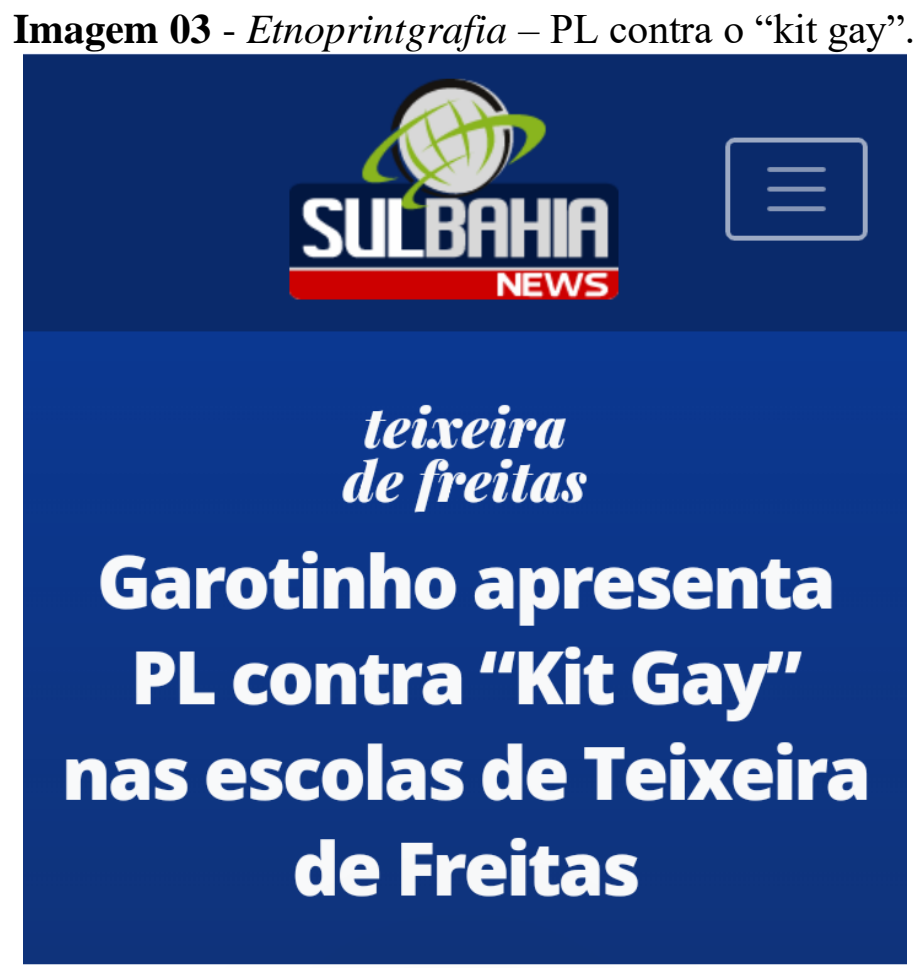

Fonte: Jornal SulBahia News

Seguem trechos da matéria:

Um dia antes de a presidente Dilma Roussef mandar suspender o kit antihomofobia, o vereador Júlio César Cavalcante, "Garotinho" (PSC), apresentou na Câmara Municipal de Teixeira de Freitas, um projeto de lei (PL) 11/2011, que proíbe a distribuição do kit nas escolas públicas da rede municipal de ensino de Teixeira de Freitas.

Para o vereador Garotinho, o kit é uma afronta aos valores familiares, "não é um projeto contra os homossexuais, porém a orientação sexual cabe somente à família. É uma vergonha um país com tanta coisa pra fazer gastar milhões com esse tipo de material, obrigando que nossos filhos tenham uma cartilha dessas, e que assistam crianças de sete anos se beijando. Isso é um desrespeito a todos princípios familiares", comentou Garotinho (SULBAHIA NEWS, 2011).

O PL apresentado e as falas do vereador Garotinho iam de encontro a um movimento protagonizado na época pelo então deputado federal Jair Messias Bolsonaro, que se posicionou contra uma política de formação continuada de professores desenvolvida pelo Programa Escola Sem homofobia do Ministério da Educação, que foi apelidado de maneira pejorativa de "kit gay”. O projeto era um recorte do Programa Brasil sem Homofobia e se destinava à formação 
DAS SEXUALIDADES NO PLANO MUNICIPAL DE EDUCAÇÃO (PME) DE

TEIXEIRA DE FREITAS - BA

continuada de professores no âmbito do Ensino Médio, atendendo também o tema transversal “orientação sexual” dos Parâmetros Curriculares Nacionais (PCN’s) de 1998, o que demonstra a não necessidade do PL construído pelo vereador Garotinho, tendo em vista que as escolas da rede municipal de Teixeira de Freitas não oferecem a modalidade do Ensino Médio.

O que apresentamos como flertes com os neoconservadorismos ainda nos anos de 2010 e 2011 se intensificaram no município. Neste sentido, apresentaremos a partir de agora, como grupos religiosos católicos e evangélicos se articularam com o legislativo municipal e discursos psicológicos numa cruzada antigêneros e diversidade sexual no PME. Neste sentido, apresentamos a etnoprintgrafia abaixo do site da Diocese de Teixeira de Freitas - Caravelas.

Imagem 04: Etnoprintgrafia - Campanha da Diocese

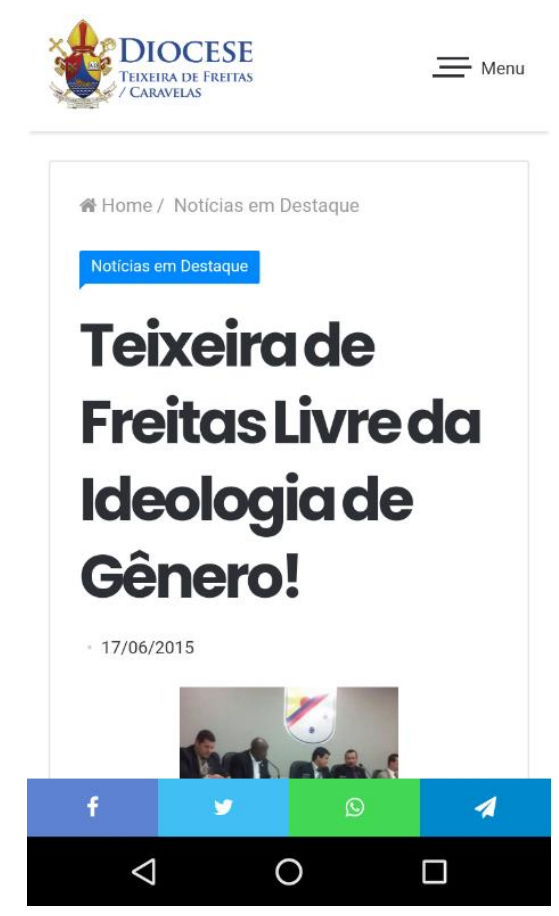

Fonte: Diocese Teixeira de Freitas/Caravelas

O site traz o trecho abaixo:

Em sessão realizada nesta terça-feira (16), na Câmara de Vereadores de Teixeira de Freitas, foi aprovado o Plano Municipal de Educação com o texto revisado e alterado.

A proposta inicial previa a inserção da Ideologia de Gênero. Após diversas mobilizações de leigos e movimentos Católicos de todo o Brasil, o plano foi modificado para que se fizesse condizente com os valores Cristãos.

Revista RBBA $\mid$ Revista Binacional Brasil Argentina 
DAS SEXUALIDADES NO PLANO MUNICIPAL DE EDUCAÇÃO (PME) DE

TEIXEIRA DE FREITAS - BA

Enfim, o município de Teixeira de Freitas está livre da inserção da Ideologia de Gênero no seu plano de educação (DIOCESE DE TEIXEIRA DE FREITAS/CARAVELAS, 2015). ${ }^{\mathrm{vi}}$

A imagem etnoprintgrafada se refere ao que foi tratado na sessão ordinária de 16 de junho de 2015, e que trazemos em trechos registrados na ata da sessão. A sessão teve sua abertura com a leitura bíblica do livro de Isaías, capítulo 54 e versículos do 13 ao 17. Dentre os pontos de pauta da sessão estão as moções de repúdio n ${ }^{\circ}$. 104/2015 de autoria dos vereadores da câmara contra os atos ocorridos na parada de orgulho gay de São Paulo no dia 07 de junho de 2015, e a nº . 106/2015 de autoria dos vereadores da câmara contra a Caixa Econômica Federal e a Petrobrás, "não por terem patrocinado a parada do orgulho gay, mas aos atos libidinosos contra símbolos religiosos, afrontando a lei, ao direito, a fé, bem como os valores das famílias cristãs" (CMTF, Ata 20/2015).

Observamos que a sessão traz duas moções de repúdio, tendo como endereçamento as políticas LGBTQIA+, o que revela o combate a essas políticas como um ponto de articulação com bancadas religiosas católicas e evangélicas, com possibilidades de aumento do eleitorado a partir dos púlpitos das igrejas. Esse movimento de uma reiteração retórica religiosa se deu “não apenas por causa do rápido crescimento do número de eleitores evangélicos, mas também pelo fato de que uma das principais candidatas [na época à presidência do Brasil], Marina Silva, ser ela mesma evangélica, o que despertou o interesse desses eleitores para escolherem um representante alinhado com suas convicções religiosas" (TOITIO, 2017, p. 4).

Dessa forma, as performances do legislativo antigêneros e diversidade sexual passaram a ser cada vez mais constantes, não se reservando aos partidos tidos como de "direita", como veremos em outros trechos, onde o vereador Ednaldo Resende dos Santos e a vereadora Erlita Conceição de Freitas, que na ocasião eram do Partido dos Trabalhadores (PT), tido como partido de "esquerda", apoiam a moção de repúdio nº 104/2015. Assim, "acostumado a conviver com a conciliação de forças contraditórias, o petismo apostou mais forte nessa forma de governabilidade" (TOITIO, 2017, p. 4).

Além das moções citadas acima, a sessão da câmara aprovou o atual PME de 2014/2024 para Teixeira de Freitas, sendo sintomáticas as falas de alguns vereadores e algumas vereadoras, que traremos aqui. Em alguns momentos a filiação partidária de alguns e algumas será mencionada, marcando que as articulações neoconservadoras não estão remetidas apenas ao 
que se tem chamado de "direita", sendo essas fronteiras rasuradas também por legisladores que estão filiados a partidos que se dizem de "esquerda".

A ata $n^{\circ}$ 20/2015, que versa acerca da sessão da Câmara Municipal de Teixeira de Freitas (CMTF) traz o seguinte trecho para se referir à fala do vereador Domingos Oliveira Donato:

[...] explicou que os termos inseridos no PME, iam de encontro a educação que se ensinava em família, pois era na família que se recebia as primeiras orientações quanto ao gênero da criança e no PME estava previsto uma orientação que daria um nó na cabeça, que o Psicólogo Senhor Leandro, foi de muita valia, esclarecendo todos sobre a ideologia de gênero, assunto que ele e grande maioria da comunidade, não sabia o que deveria ler nas entrelinhas sobre o assunto ideologia de gênero" (CMTF, 2015, p. 4) (grifo nosso).

O vereador Moacir Oliveira de Souza pontuou:

“[...] esta casa contou com a ajuda do psicólogo Leandro para prosseguir com os estudos do mesmo [PME], que foi detectado alguns pontos no projeto e no Plano, mas que foi solucionado o caso, que líderes religiosos de muitos segmentos participou das reuniões para cientificá-los, dos perigos nas entrelinhas, que houve consenso entre os poderes e a mudança no plano foi feita" (CMTF, 2015, p. 4) (grifo nosso).

Observamos nas falas dos vereadores acima, que as articulações neoconservadoras no PME também contaram com os discursos psicológicos na produção de regimes de verdades (FOUCAULT, 1999) - os quais operam para conduzir condutas -, caminhando ao lado de discursos religiosos para "cientificar" o Plano, conforme o grifo na fala do vereador Moacir Oliveira. Para as articulações neoconservadoras o discurso religioso não basta, sendo necessária uma aproximação com a cientificidade. No caso do PME de Teixeira de Freitas, essa cientificidade estava representada pelo discurso psicológico e a autoridade do psicólogo, onde as articulações ocorreram "por meio de muitas disputas por hegemonizar determinadas fixações de sentidos que possuem efeitos de verdades, são investidos de poderes que interferem na vida, nas ações, nas emoções e nos corpos das populações" (CRUZ; SILVA; SANTOS, 2020, p. 94).

Ao voltarmos para a análise de Apple (2000, 2001, 2013) com os quatro grupos que compõem a "Nova Direita" nos EUA, percebemos nos discursos dos vereadores abaixo uma vinculação com o grupo dos populistas autoritários, performatizando uma narrativa imbricada em valores religiosos e em defesa da família. O vereador Ronaldo Alves Cordeiro já inicia a sua fala como segue no registro:

Revista RBBA 
[...] frizou como regra de fé a Bíblia Sagrada, que o homem com temor a Deus se desviava do mal [...] que defendia os princípios da família, que esta casa atuava com responsabilidade, que o plano municipal de educação era muito importante ao município, mas a ideologia de gênero de maneira suavizada que constava no bojo do projeto fora detectado e retirado do mesmo, se manifestou contra a ideologia de gênero" (CMTF, 2015, p. 6) (grifo nosso).

Adotando um tom parecido, o vereador Yuri Takao Shinozaki disse que "o Secretário de Educação fora infeliz quando disse que os pastores não participam da elaboração do plano, pois função do pastor era cuidar do seu rebanho e não da educação da cidade, que o PME estava indo contra a família, contra a religião, que esta casa não foi irresponsável quanto a análise do projeto" (CMTF, 2015, p. 5) (grifo nosso).

As falas dos vereadores alicerçadas num discurso religioso marca, como já apresentado, um movimento de cortejamento de partidos e pleitos políticos aos grupos religiosos, que tiveram sua ascensão em 2010, onde “a 'Carta ao povo de Deus' foi o primeiro indício de como o governo Dilma trataria as políticas e os direitos sexuais: estes só seriam disputados pelo governo na medida em que não afetassem sua política de alianças, cuja composição incluía partidos conservadores" (TOITIO, 2017, p. 8). Desta forma, vereadores do município de Teixeira de Freitas, que tinham uma aproximação com as pautas LGBTQIA+, como o Ednaldo Resende dos Santos, que em 2011 participou e foi o único a apoiar a "Conferência Territorial de Políticas Públicas LGBT do Extremo Sul da Bahia”, conforme podemos observar em foto abaixo, passa a assumir em 2015 uma postura neoconservadora antigêneros e sexualidades. 

DAS SEXUALIDADES NO PLANO MUNICIPAL DE EDUCAÇÃO (PME) DE TEIXEIRA DE FREITAS - BA

Imagem 05 - Grupo de discussão na Conferência Territorial LGBT

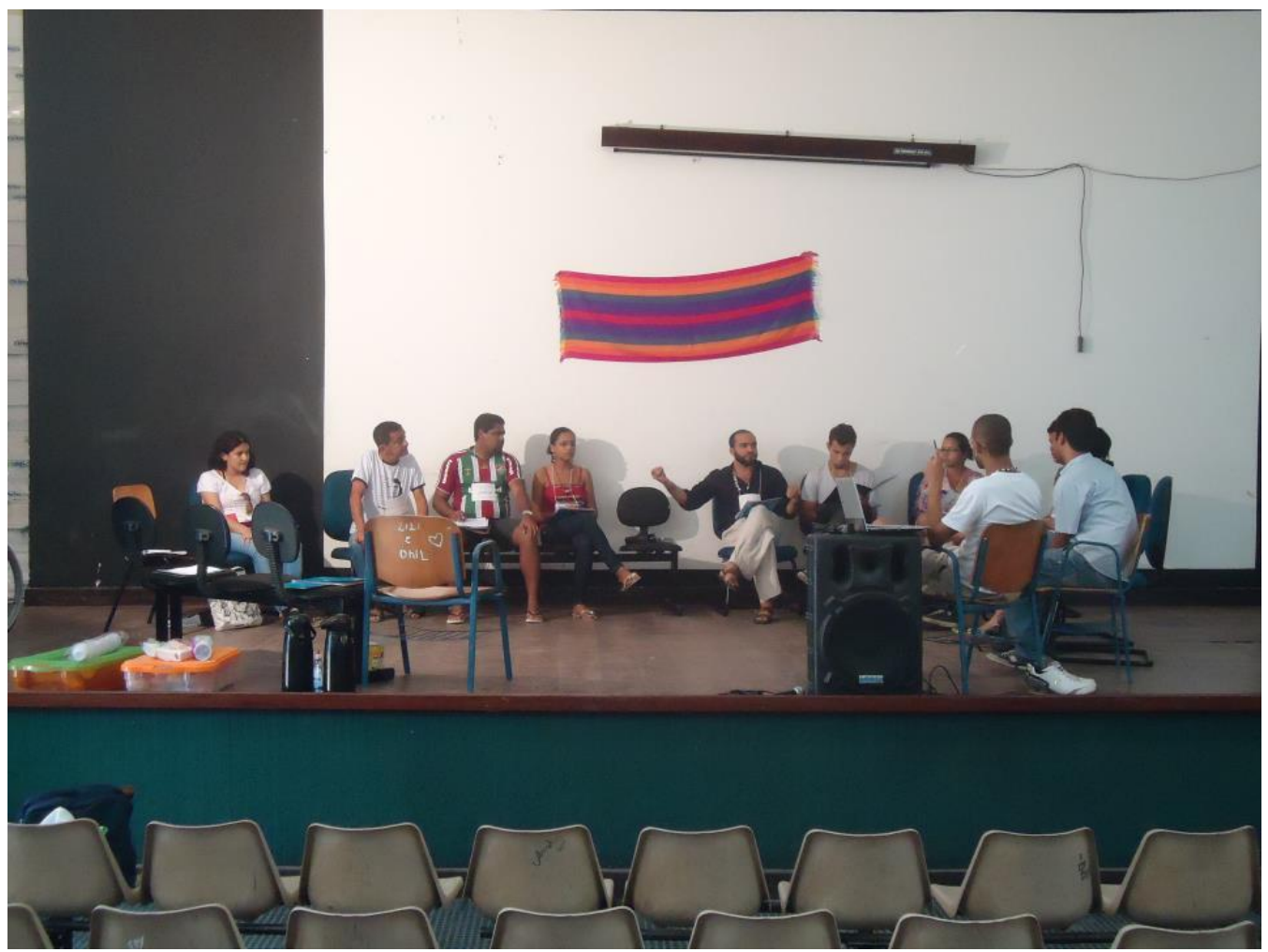

Fonte: Acervo Coletivo Corphus

Assim como o vereador Ednaldo Resende, não adotando uma performance diferente dos partidos intitulados de direita, a vereadora Erlita Conceição de Freitas (PT) apoiou a moção de repúdio n”. 104/2015, "falando da importância do Plano Municipal de Educação para Teixeira de Freitas, que as discussões a respeito do mesmo, teve a participação da comunidade, da Secretaria Municipal de Educação que entraram em consenso, para o melhor pra família Teixeirense" (CMTF, 2015, p. 5) (grifo nosso). O consenso referido pela vereadora faz parte de alianças com os grupos religiosos, que na fala do vereador Tomires Babosa Monteiro vai para além do caráter laico do Estado brasileiro. Para o vereador Tomires Babosa “o estado laico não permitia que se fizesse todas as coisas não, pois tinha imparcialidade quanto a religião, que esta casa havia se atentado para a maneira sutil relatada no Plano Municipal de Educação, da questão da identidade de gênero" (CMTF, 2015, p. 7) (grifo nosso). Na observação do vereador Tomires Babosa, percebemos uma tentativa de descolar o silenciamento e a exclusão das questões de gêneros e sexualidades dos discursos religiosos, o que entendemos ser impossível, tendo em vista que as articulações foram feitas com 
ARTICULAÇÕES NEOCONSERVADORAS EM TORNO DOS GÊNEROS E

DAS SEXUALIDADES NO PLANO MUNICIPAL DE EDUCAÇÃO (PME) DE

TEIXEIRA DE FREITAS - BA

representantes de igrejas cristãs católica e evangélica, estando os argumentos apresentados e fundamentados nos valores cristãos.

\section{(In)conclusões}

A pesquisa aponta redes de influências representadas por grupos religiosos em articulações com discursos psicológicos e o legislativo municipal, no silenciamento e exclusão em torno das questões de gêneros e sexualidades no PME do município de Teixeira de FreitasBA, contribuindo para a manutenção de uma educação "marcada pelos traços dominantes da nossa cultura católica [e agora também evangélica], agrícola e escravocrata, refletidos em um sistema de ensino desorganizado, elitista e seletivo" (RANIERI, 2018, p. 16). Observamos que tais articulações vêm sendo construídas antes de 2015, ano de aprovação do PME, reiterando um movimento nacional neoconservador, que se torna mais visível a partir do ano de 2010.

Em Teixeira de Freitas, percebemos ainda que as articulações feitas em torno das questões de gêneros e sexualidades impediram processos formativos na rede municipal, silenciando questões importantes na equidade dos gêneros e na superação das LGBTfobias. Assim, “[...] o lugar do[s] gênero[s] e da produção das sexualidades nas políticas de educação é um lugar ainda por se consolidar" (VIANNA; BORTOLINI, 2020, p. 19), sendo importante que a rede municipal reveja e atualize o seu PME dentro dos princípios constitucionais da laicidade, garantido a construção de educações não sexistas e não LGBTfóbicas.

\section{REFERÊNCIAS}

AMARO, Ivan. A docência no armário: o silenciamento das relações de gênero nos planos de educação. Revista Espaço Pedagógico, v. 24, n. 1, 5 maio 2017.

APPLE, Michael W. Política Cultural e Educação. Tradução de José do Amaral Ferreira. São Paulo: Cortez, 2000.

APPLE, Michael W. Reestruturação Educativa e Curricular e as Agendas Neoliberal e Neoconservadora: Entrevista com Michael Apple. Currículo sem Fronteiras, v.1, n.1, p.533, Jan/Jun 2001.

APPLE, Michael W. Fazendo o trabalho de Deus: ensino domiciliar e trabalho de gênero. In: APPLE, M. W.; BALL, S. J.; GANDIN, Luís Armando. Sociologia da Educação: análise internacional. Tradução de Cristina Monteiro. Porto Alegre: Penso, 2013. 
DAS SEXUALIDADES NO PLANO MUNICIPAL DE EDUCAÇÃO (PME) DE

TEIXEIRA DE FREITAS - BA

BORGES, Luzineide Miranda. \#Soudoaxé: redes educativas e o ciberativismo da Juventude de Terreiro da nação Ijexá. Tese (Doutorado em Educação). ProPED, UERJ, 2019.

BRASIL. Projeto de Lei do Plano Nacional de Educação (PNE 2011-2020): Projeto em tramitação no Congresso Nacional - PL nº 8.035/2010. Brasília: Câmara dos Deputados, Edições Câmara, 2011 (Série Ação Parlamentar, 436).

BROWN, Wendy. Nas ruinas do neoliberalismo: a ascensão da política antidemocrática no ocidente. São Paulo: Editora Filosófica Politeia, 2019.

CÂMARA MUNICIPAL DE TEIXEIRA DE FREITAS (CMTF). Ata n⿳. 20 de 2015. Teixeira de Freitas: CMTF, 2015.

CRUZ, Thalles do Amaral de Souza; SILVA, Marlon Silveira da; SANTOS. João Paulo Lopes dos. Da educação sexual à "ideologia de gênero": disputas em torno das sexualidades e dos gêneros na escola. Pró-Discente: Caderno de Produção Acadêmico-Científica. VitóriaES, v. 26, n. 1, p. 91-107, jan./jun. 2020.

FOUCAULT, Michel. A ordem do discurso. São Paulo: Loyola, 1999

LIMA, Iana Gomes de; HYPÓLITO, Álvaro Moreira. A expansão do neoconservadorismo na educação brasileira. Educ. Pesqui., São Paulo, v. 45, e190901, 2019.

MACEDO, Elizabeth. Base Nacional Curricular Comum: novas formas de sociabilidade produzindo sentidos para educação. Revista e-Curriculum, São Paulo, v. 12, n. 03 p.1530 1555 out./dez., 2014.

MACEDO, Elizabeth. As demandas conservadoras do movimento escola sem partido e a base nacional curricular comum. Educ. Soc. Campinas, v. 38, nº. 139, p.507-524, abr./jun., 2017.

MACEDO, Elizabeth. Repolitizar o social e tomar de volta a liberdade. EDUR- Educação em Revista. Belo Horizonte. v. 34, e212010, 2018.

MIGUEL, Luis Felipe. Da “doutrinação marxista" à "ideologia de gênero" - Escola Sem Partido e as leis da mordaça no parlamento brasileiro. Revista Direito \& Práxis. Rio de Janeiro, vol. 07, n. 15, 2016, p. 590-621.

PARAISO, Marlucy Alves. Currículo, gênero e heterotopias em tempos do slogan "ideologia de gênero". In: LOPES, Alice Casimiro; OLIVEIRA, Anna Luíza A. R. Martins de; OLIVEIRA, Gustavo Gilson Sousa de (Org.). Os gêneros da escola e o (im)possível silenciamento da diferença no currículo. Recife: Ed. UFPE, 2018.

RANIERI, Nina Beatriz Stocco. Educação obrigatória e gratuita no Brasil: um longo caminho, avanços e perspectivas. In: RANIERI, Nina Beatriz Stocco; ALVES, Ângela Limongi Alvarenga (Orgs.). Direito à educação e direitos na educação em perspectiva interdisciplinar. São Paulo: UNESCO/USP, 2018. 

DAS SEXUALIDADES NO PLANO MUNICIPAL DE EDUCAÇÃO (PME) DE TEIXEIRA DE FREITAS - BA

RODRIGUES, Julian; FACCHINI, Regina. "Ideologia de gênero", atores e direitos em disputa: uma análise sobre o processo de aprovação do Plano Nacional de Educação (2013 2015). In: LOPES, Alice Casimiro; OLIVEIRA, Anna Luíza A. R. Martins de; OLIVEIRA, Gustavo Gilson Sousa de (Org.). Os gêneros da escola e o (im)possível silenciamento da diferença no currículo. Recife: Ed. UFPE, 2018.

VIANNA, Cláudia; BORTOLINI, Alexandre. Discurso antigênero e agendas feministas e LGBT nos planos estaduais de educação: tensões e disputas. Educ. Pesqui., São Paulo, v. 46, e221756, 2020.

TOITIO, Rafael Dias. A disputa entre movimento LGBT e neoconservadorismo religioso no governo Dilma. $4^{\circ}$ Encontro Anual da Anpocs GT 8 - Democracia e Desigualdades, 2017.

\section{Notas}

i “Ideologia de gênero" é uma expressão cunhada fora dos meios governamentais ou acadêmicos e difundida pelo ativismo religioso, especialmente o católico, nos últimos anos. Não se trata, portanto, de um termo que conste nos marcos legais brasileiros, ou mesmo no repertório dos movimentos LGBT e feministas, na literatura das Ciências Humanas e Sociais ou nos estudos de gênero e feministas (RODRIGUES; FACCHINI, 2018, p. 102).

ii $h$ ttps://dioceseteixeiradefreitas.com.br/895/ . Acesso em 25 de setembro de 2020.

iii Disponível em: http://www.escolasempartido.org/quem-somos/. Acesso em: 09 set 2020.

iv https://www.sulbahianews.com.br/vereador-garotinho-repudia-o-grupo-gay-da-bahia-ggb/ Acesso em $25 \mathrm{de}$ setembro de 2020.

${ }^{v}$ https://osollo.com.br/garotinho/. Acesso em 25 de setembro de 2020.

${ }^{\mathrm{vi}}$ https://dioceseteixeiradefreitas.com.br/906/ . Acesso em 25 de setembro de 2020. 